\title{
MICROSTRUCTURAL CHARACTERIZATION OF THE Cu-TiB 2 ALLOY BY ELECTRON MICROSCOPY
}

\author{
D. Corredor, M. López, C. Camurri, V. Vergara y J. Jiménez \\ Universidad de Concepción, Departamento de Ingeniería Metalúrgica, Casilla 53-C, Concepción, Chile, e-mail \\ marlope@udec.cl \\ *Centro de Investigaciones Metalúrgicas (CENIM), Av. Gregorio del Amo 8-28040, Madrid, España.
}

The alloy was elaborated with pure powders of copper and titanium borides, by mechanical alloying. The milling was made in a planetary mill by using martensitic stainless steel recipients and balls, for variable periods of time with the purpose of evaluating the homogeneity, morphology and grain size reduction of ceramic dispersed by means of X-ray diffraction and microstructural characterization. The factors that affect the formation of the phases in the material are: type mill, copper grain size, atmosphere of the process, amount of process control agent, ratio of ball weight /powder weight, time and ceramic percentage. It is known a priori that the materials obtained by this process present a better homogeneity in the composition and a size of grain finer than the ones obtained by conventional methods, and that it also allows the elaboration of only feasible alloys to high temperatures by the conventional process.

By means of hot uniaxial pressing, 25 gr. of the alloyed powders were consolidated applying a pressure of $90 \mathrm{MPa}$ at $650^{\circ} \mathrm{C}$, during $2 \mathrm{~h}$ in argon atmosphere. Finally these pressed powders were hot rolled at $850^{\circ} \mathrm{C}$ with $20 \%$ reduction. The microstructural evolution was studied by means of the microstructural characterization (SEM, TEM, and Microprobe) of alloyed consolidated powders.

Figure 1, SEM Micrographs shows morphology and particles size for $\mathrm{Cu}-\mathrm{TiB}_{2}$ alloys with two different ceramic percentages, alloyed mechanically during 36h. Figure 2a, TEM Micrographs of $\mathrm{Cu}_{-} \mathrm{TiB}_{2}$ (1\%) 36h (M.A). Dark particles within the clear zone would be the borides. On the bottom right hand side the boride particles are shown in dark field. Figure $2 b$, The chromium and iron presented in the EDAX Spectra arise from the wearing of milling means. Figure 3, EPMA BEI Image of consolidated alloy for $12 \mathrm{~h}$ and $36 \mathrm{~h}$ respectively. Figure 4, Is observed the grain size reduction and more homogeneity in $36 \mathrm{~h}$ alloy, not observed residual particle free copper.

\section{ACKNOWLEDGEMENT}

This study was supported by the Dirección de Investigación de la Universidad de Concepción, Proyecto 99.095.063-1.0, FONDECYT, Proyecto N 1000476 and CENIM.

\section{REFERENCES}

1. C.Biselli, et al. Mechanical Alloying of High-Strength Copper Alloys Containing $\mathrm{TiB}_{2}$ and $\mathrm{Al}_{2} \mathrm{O}_{3}$ Dispersoid Particles. Scripta Met et Materialia, Vol. 30, No 10, pp 1327-1332 (1994).

2. M.López, C.Camurri, V.Vergara, D.Corredor and J.Jiménez. Estructura y Propiedades del Material Compuesto de Base Cobre Reforzado con Partículas Intermetálicas de TiB2. IV Encuentro de Ingeniería de Materiales. Materiales 2002. Habana, Cuba, Septiembre 24-27 (2002). 

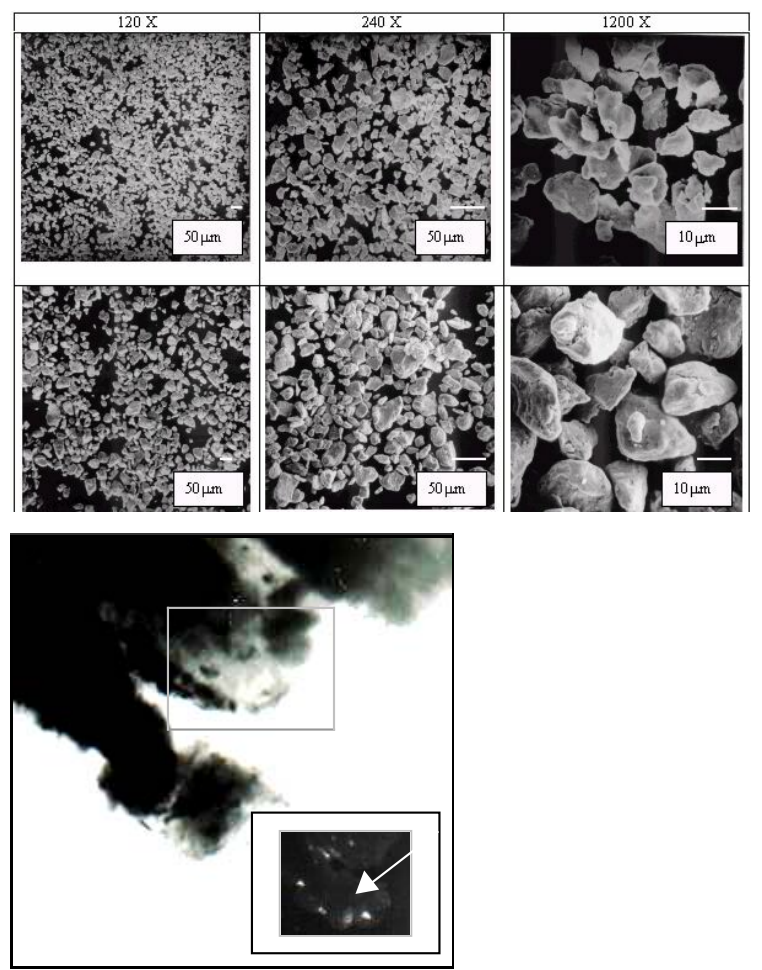

Figure 2a Photomicrograph by TEM 200K. For $\mathrm{Cu}-\mathrm{TiB}_{2}$ (1\%) 36h, M.A., wearing with dimple and electropolishing.
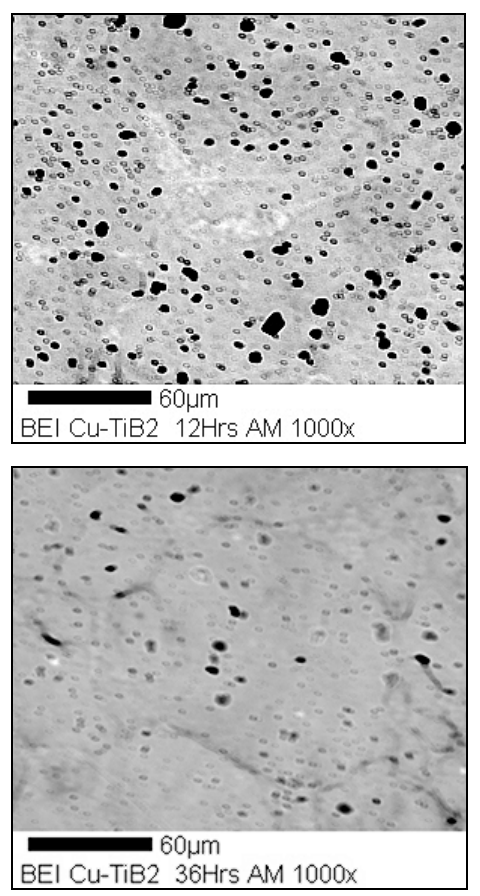

Figure 3. EPMA BEI image of consolidated Alloy for $12 \mathrm{~h}$ and $36 \mathrm{~h}$ M.A.
Figure 1. Morphology and particle size of alloys $\mathrm{Cu}-\mathrm{TiB}_{2}(1 \%)$ y $(2 \%)$ respectively.

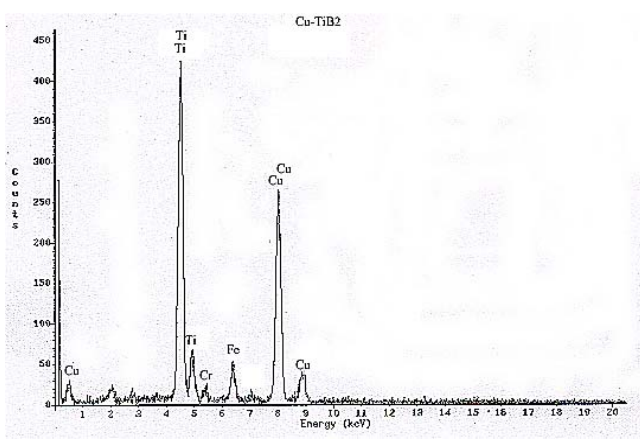

Figure $2 \mathrm{~b}$ EDAX Spectra corresponding to the figure (a).
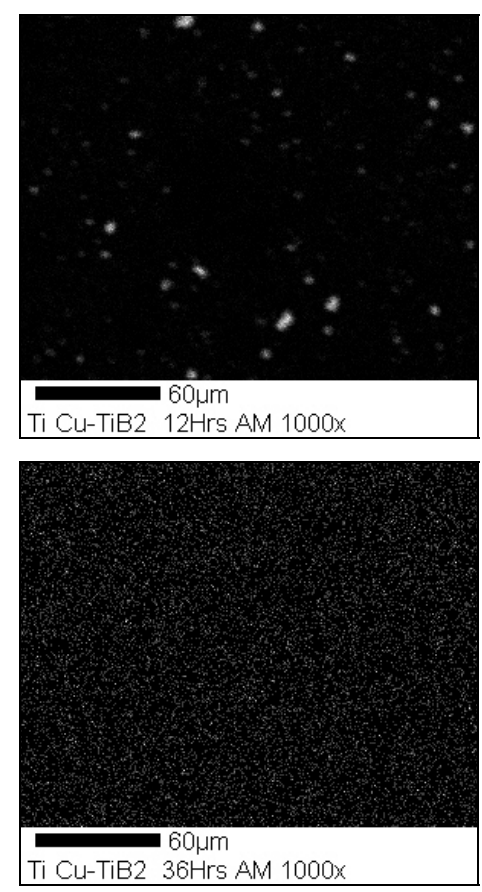

Figure 4. X-ray intensity map for titanium For $12 \mathrm{~h}$ and $36 \mathrm{~h}$ M.A. 
https://doi.org/10.1017/S1431927603443146 Published online by Cambridge University Press 